\title{
Darwinismo e ciências sociais: um diálogo possível
}

\author{
ENTREVISTA COM GEOFFREY M. HODGSON
}

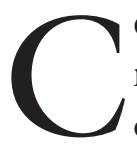

ONSIDERADO pelos especialistas o principal teórico da economia evolucionista da atualidade, o economista inglês Geoffrey M. Hodgson defende que princípios darwinistas constituem o arcabouço teórico mais adequado para entender os processos evolutivos nas esferas social e econômica. "Um esforço paralelo, com o qual também me envolvi, é o de mostrar como os princípios abstratos essenciais do darwinismo também se aplicam a entidades socioeconômicas em evolução tais como empresas", diz.

$\mathrm{O}$ economista respondeu às perguntas ${ }^{1}$ da entrevista por escrito diretamente da University of Hertfordshire, Reino Unido, Inglaterra, onde leciona Business studies, e as enviou por e-mail.

Geoffrey M. Hodgson é editor do Journal of Institutional Economics, publicado pela Cambridge University Press, autor de artigos publicados em jornais e revistas acadêmicas, além de 12 livros, entre eles, Economics in the shadows of Darwin and Marx: essays on institutional and evolutionary themes (2006); The evolution of institutional economics: agency, structure and darwinism in american institutionalism (2004); How economics forgot history: the problem of historical specificity in social science (2001); Evolution and institutions: on evolutionary economics and the evolution of economics (1999); Economics and utopia: why the learning economy is not the end of history (1999); Economics and evolution: bringing life back into economics (1993).

ESTUDOS AVANÇADOS - De que maneira, na sua opinião, o darwinismo pode nos ajudar a entender processos de evolução nas esferas social ou econômica?

Geoffrey M. Hodgson - Temos de considerar as condições ontológicas mínimas nas quais se dá a evolução darwinista. Imagine uma população de entidades que interagem com seu ambiente, consomem energia ou matéria para sobreviver e preservam e transmitem informações relevantes para a sobrevivência. Elas são o que podemos chamar de "sistemas populacionais complexos". Facilmente se deduz que, para entender a evolução de um sistema como esses, precisamos das idéias darwinianas de variação, herança e seleção. Em outras palavras, temos de entender os mecanismos necessários para criar e sustentar a variação, as maneiras pelas quais informações relevantes são preservadas e transmitidas e os processos que levam à sobrevivência de algumas entidades e de fragmentos de informações e não de outros. Todas essas questões devem ser analisadas. Fora do 
darwinismo, não há outro arcabouço teórico adequado para entendermos esses processos evolucionários.

Populações de organismos naturais são, claramente, "sistemas populacionais complexos". Podemos incluir também populações de robôs ou de autômatos auto-replicantes. Vários autores argumentam que coleções de entidades sociais são sistemas populacionais complexos no sentido que descrevi. Thorstein Veblen, por exemplo, escreveu sobre a "seleção natural de instituições". Seguindo esses autores, minha pesquisa discute unidades sociais de evolução e a possibilidade de que princípios darwinistas se apliquem a alguns conjuntos de organizações, incluindo empresas.

Os princípios darwinistas não implicam necessariamente que os resultados de um dado processo evolucionário são mais eficientes e mais desejáveis. Darwin escreveu em A origem do homem: "Tendemos a ver o progresso como a regra normal da sociedade humana; mas isso a história refuta". Mais ainda, Darwin reconhece uma função para a cooperação tanto quanto para a competição, e ele não endossou nem o racismo nem o nacionalismo.

Estudos AVANÇADOs - Se o desenvolvimento econômico e social resulta da ação recíproca de forças cegas do processo evolucionário, qual seria o papel da crítica racional e dialética?

G. M. H. - Descrever um processo darwinista como "cego" é, na melhor das hipóteses, equivocado. Se a evolução envolve organismos que vêem, então eles usam sua visão para interagir com seu ambiente e melhorar suas probabilidades de sobrevivência. Usando informações de seus órgãos sensoriais, alguns animais param, deliberam e consideram opções futuras. Os seres humanos têm capacidades bem desenvolvidas para a previsão e muitas de nossas ações são intencionais ou conscientes. A descrição equivocada do processo evolucionário como "cego" sugere outras coisas.

Uma palavra melhor seria "não-projetado". Embora os seres humanos tenham planos e intenções, as estruturas sociais são tão complexas que os resultados não podem ser completamente previstos. Há conseqüências não-intencionais. Da mesma forma, há na natureza fenômenos padronizados que evoluíram sem projeto. O darwinismo nos ajuda a explicar como esses resultados complexos evoluem sem pressupor um projeto ou projetista global. Mas o darwinismo não exclui a intencionalidade, a deliberação ou a previsão. Em princípio, ele é compatível tanto com a deliberação racional quanto com o diálogo interativo relativo a estratégias de cooperação em grupos. Quando consideramos a evolução social, é preciso reconhecer que a prefiguração, a deliberação e a comunicação desempenham um papel muito mais importante na espécie humana do que em qualquer outra. Mas isso não quer dizer que o darwinismo é inadequado.

Estudos AvanÇADos - Qual é sua avaliação das idéias de Richard Dawkins, particularmente daquelas que se opõem a posições defendidas por Stephen Jay Gould? 
G. M. H. - Dawkins é biólogo e Gould foi paleontólogo. Ambos são autores brilhantes e inspiradores. Todavia, eu não sou nem biólogo nem paleontólogo, e não tenho o conhecimento necessário para lidar de forma adequada com todas as suas controvérsias no âmbito dessas disciplinas. Contudo, não me convence nem a visão da evolução biológica muito "centrada no gene" de Dawkins nem a sua rejeição de seleção de grupo. $\mathrm{O}$ endosso por parte de Gould dos múltiplos níveis de seleção é mais convincente.

Em contrapartida, há menos diferença entre eles do que parece no que se refere aos "equilíbrios pontuados" na evolução biológica. Dawkins aceita que a velocidade da mudança na evolução biológica às vezes pode ser mais rápida do que em outros tempos. Em conseqüência disso, os equilíbrios pontuados são perfeitamente consistentes com a perspectiva darwinista. A investigação da existência ou não de surtos acelerados no processo evolucionário é uma questão empírica, não um caso de uma doutrina a priori.

Está claro, porém, que tanto Dawkins quanto Gould causaram um impacto adicional nas ciências sociais e na filosofia da ciência. Nessas áreas estou mais preparado. Nesse terreno vejo virtudes e defeitos nos dois autores.

Uma idéia importante nos escritos de Dawkins é a noção de que o darwinismo não se aplica simplesmente ao mundo biológico; ele incorpora um conjunto de princípios que ajudam a explicar a evolução na esfera social e em outras esferas. Nesse ponto eu acho que Dawkins está absolutamente certo, mas eu preferiria chamar esse darwinismo de "generalizado" e não de "universal", por não se aplicar necessariamente a todos os fenômenos. Ele exige algumas precondições ontológicas mínimas, como já descrevi em linhas gerais respondendo a uma questão anterior.

Além disso, a idéia de generalizar o darwinismo para a evolução social já se encontra em autores anteriores, inclusive no próprio Darwin. Walter Bagehot, William James, Thorstein Veblen, Albert Keller, Donald Campbell, Friedrich Hayek e vários outros utilizaram essa noção. Dawkins não foi o primeiro a sugerir que o cerne dos princípios darwinistas se aplica à evolução social, mas ele parece ignorar seus antecessores.

Quando Dawkins tenta lidar com a evolução social, surgem problemas no nível dos detalhes. Ele adota o termo "meme" (mais uma vez há antecessores que ele não reconhece) e faz dele a unidade da evolução no nível social. Como sublinha David Hull, isso cria um paradoxo no texto de Dawkins admitindo a possibilidade da evolução em múltiplos níveis, em contraste com sua visão "centrada no gene". Tampouco está claro o que seja um meme. Memes são idéias, comportamentos ou traços de memória no cérebro? A menos que essas questões sejam respondidas, a natureza de um meme permanece vaga demais, não se sabendo mesmo se o meme é como um genótipo ou como um fenótipo. Embora a obra de Dawkins tenha inspirado uma nova ciência da "memética", o projeto inteiro encalha por falta de respostas claras a essas questões fundamentais. Al- 
guns pesquisadores, eu incluído, estão tentando estabelecer detalhadamente a natureza e identidade de unidades de evolução no nível social. Palavras que tudo abrangem, como o termo "meme", pouco ajudam.

Contrastando com Dawkins, Gould acreditava que as idéias darwinistas não se aplicam à evolução social. Acho que o argumento dele é muito fraco. Gould ressalta que as entidades e mecanismos da evolução biológica são muito diferentes daqueles da esfera social. É óbvio que são muito diferentes. Mas também há diferenças entre entidades e mecanismos dentro do mundo biológico. As plantas e os mamíferos se reproduzem de modos muito diferentes, e há outros replicadores biológicos além do DNA. No entanto, o darwinismo se aplica a todos esses diferentes fenômenos. O darwinismo não explica todos os detalhes: trata-se de um arcabouço metateórico para organizar explicações detalhadas, de domínios específicos. Nesse nível metateórico, o darwinismo também se aplica ao domínio social. A generalização do darwinismo não diz respeito a analogias biológicas; diz respeito a características ontológicas comuns num nível muito abstrato. Lamentavelmente, parece que Gould nunca entendeu esse argumento. Ele simplesmente o descartou em sua radical e maldefinida condenação do "hiperdarwinismo".

David Sloan Wilson faz uma observação interessante em sua resenha do seu livro campeão de vendas The God Delusion [ $A$ ilusão de Deus] de 2006. (Essa resenha pode ser acessada na página eletrônica de Wilson.) Como Dawkins, Wilson é ateu. Mas, ao contrário de Dawkins, ele é um expoente da seleção de grupo. Wilson ressalta que a religião desempenhou um papel importante na promoção da coesão e do valor de sobrevivência dos grupos humanos. Conseqüentemente, a religião é uma adaptação cultural. Wilson nos lembra então da posição de Gould contra o "adaptacionismo" e de sua reivindicação de que muitos resultados biológicos não são adaptações num sentido efetivo. (Uma boa crítica da posição de Gould sobre esse ponto se encontra no livro de Daniel Dennett, Darwin's Dangerous Idea [A perigosa idéia de Darwin].) Wilson faz em seguida uma brilhante observação dizendo que Dawkins e Gould têm a culpa de não reconhecerem adaptações reais. Gould ignora adaptações no mundo biológico e Dawkins na esfera social. Nessa falha comum, eles partilham mais do que parece à primeira vista.

Estudos AVANÇADOS - Qual é a sua avaliação do livro de Daniel C. Dennett, Darwin's Dangerous Idea (1995)?

G. M. H. - É um livro inspirador, uma leitura essencial. Contém muitas idéias importantes e está escrito numa forma convincente. Aceito grande parte do argumento central desse volume, mas discordo de alguns detalhes. Entre os pontos positivos está a explicação clara de por que os princípios centrais do darwinismo se aplicam à evolução mesmo além do domínio biológico. Todavia, como Dawkins, Dennett adota o conceito vago do "meme", e sua explicação imprecisa da evolução social padece de problemas e limitações semelhantes. 
Geoffrey M. Hodgson.

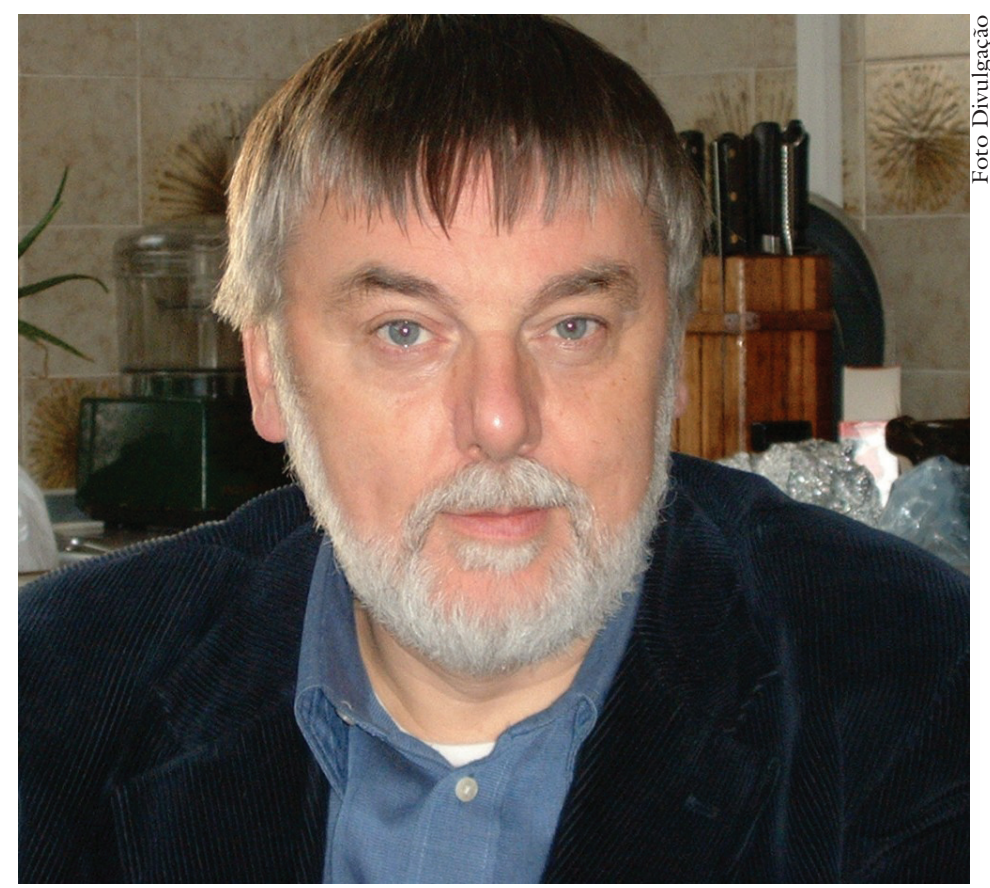

Além disso, como Dawkins, Dennett reluta em considerar a possibilidade de níveis mais altos de evolução, incluindo a seleção de grupo. Toda a sua discussão de "reducionismo" é sintomática. Sua condenação do pecado do "ávido reducionismo" é confusa porque o reducionismo é voraz por sua própria natureza. Dennett ignora a possibilidade de que reduções explanatórias completas em termos de entidades de níveis mais baixos possam ser bloqueadas pela existência de propriedades emergentes. Ao contrário de Karl Popper e de outros importantes filósofos da ciência, ele parece pensar que essas reduções explanatórias completas são geralmente possíveis.

Segundo Dennett, os que são culpados de "ávido reducionismo... subestimam as complexidades, numa tentativa de passar por cima de camadas ou níveis teóricos em sua pressa de amarrar tudo de forma segura e precisa ao fundamento!". Todavia, essas pessoas não são apenas culpadas do pecado da ganância, mas também da pressa e do desleixo. A rejeição por parte de Dennett do "ávido reducionismo" é essencialmente uma tentativa fracassada de purificar o reducionismo de seus temerários dissidentes e preservar as credenciais reducionistas respeitáveis. Como acontece com Dawkins, seus sentimentos reducionistas o levam a ignorar a existência da evolução em múltiplos níveis.

Uma das idéias mais positivas e importantes desse livro, elaborada por Dennett de forma brilhante, contudo, diz respeito à natureza "algorítmica" de um processo evolucionário darwiniano. É algorítmica por envolver uma explicação causal detalhada, seqüencial, não-teleológica. Em meu livro The Evolution of Institutional Economics [A evolução da economia institucional] de 2004, argumento que Veblen também entendeu a evolução darwinista nesses termos, 
mas empregou a expressão “causação cumulativa” em vez de “algorítmica” para descrever esse processo darwinista. Nessa área há um importante ponto de convergência entre Veblen e Dennett.

ESTUDOS AVANÇADOS - Que dizer da obra de Peter J. Richardson e Robert Boyd, Not by Genes Alone: How Culture Transformed Human Evolution [Não só pelos genes: como a cultura transformou a evolução humana] (2005)?

G. M. H. - Esse é outro livro importante e muito instigante. Ele amplia e atualiza o clássico anterior desses autores sobre Culture and the Evolutionary Process [A cultura e o processo evolucionário] de 1985, que ajudou a revolucionar nosso entendimento da evolução cultural e social e de seu relacionamento com a mudança biológica e genética. Sua idéia da "dupla herança” é muito útil e importante; é um antídoto contra reducionistas biológicos que querem explicar tudo em termos biológicos e genéticos. Sua brilhante obra inspirou toda uma série de outras questões de pesquisa e investigações detalhadas. Trata-se de um grande feito de suma importância para as ciências sociais do século XXI.

Tenho algumas pequenas objeções. A definição deles de cultura é superficial, e eles não exploram adequadamente os mecanismos detalhados da preservação e replicação de informações. Também concordo com a crítica de W. G. Runciman a Boyd e Richerson em seu ensaio no livro The Evolution of Cultural Entities [A evolução de entidades culturais] (2002, organizado por Michael Wheeler, John Ziman e Margaret Boden). Runciman ressalta que uma explicação adequada de evolução social deve incluir o establishment e a replicação de posições sociais e políticas, bem como de crenças ou práticas culturais.

ESTUDOS AVANÇADOS - Como você resumiria a sua controvérsia com Richard T. Nelson e Sidney G. Winter?

G. M. H. - Primeiro, quero enfatizar o meu alto grau de concordância com a abordagem deles e reconhecer que ela tem sido de extrema inspiração para a minha obra. Publiquei, na Cambridge Journal of Economics, em 1994, um artigo sobre a importante mas esquecida crítica que Winter fez a Milton Friedman. Mostrei alguns problemas técnicos na argumentação de Winter, mas em geral meu objetivo foi trazer para esse artigo esquecido a atenção de uma platéia maior, cada vez mais interessada em idéias evolucionárias. O trabalho de Winter está décadas à frente de sua hora, e continua sendo menos lido e menos citado do que deveria ser.

Em seu livro de 1982, Nelson \& Winter se descrevem ardorosamente como "lamarckistas", mas não esclarecem o que isso significa. Querem dizer que são "lamarckistas” em biologia, bem como em economia evolucionária? Essa seria uma posição arriscada contra a ortodoxia biológica corrente, e uma posição desnecessária para a sua argumentação teórica em economia. Ou será que eles queriam dizer que acreditavam que a evolução socioeconômica era lamarckista, diferentemente da evolução biológica? Estou cada vez mais convencido de que essa invocação da lamarckismo não satisfaz e confunde, mesmo que se restrinja ao terreno socioeconômico. 
Ironicamente, em oposição a isso, Darwin é mencionado apenas uma vez (de passagem) em todo o volume. No entanto, em sua teoria evolucionária, os princípios darwinistas de variação, herança e seleção são claros e centrais. Igualmente, num espírito darwiniano moderno, eles utilizam termos como "rotinas como genes". Tenho a impressão de que eles haviam adotado os princípios darwinistas essenciais, mas relutavam ao máximo em admiti-lo. Mais recentemente, porém, eles reconheceram o caráter darwinista do seu pensamento.

Alguns outros pontos de divergência permanecem. Observei que Nelson \& Winter referem-se a "rotinas como genes" em seu livro de 1982. Até pouco tempo atrás, Nelson continuou argumentando que as rotinas pareciam "genótipos" e as empresas pareciam "fenótipos". Eu acho que uma forma de distinção genótipo-fenótipo existe na evolução social, e para descrevê-la emprego a terminologia mais geral de replicador-interator. Penso que essa distinção é importante num processo evolucionário para mostrar quais mecanismos carregam e replicam informações e quais entidades interagem com o ambiente para causar replicações diferenciais. Ironicamente, a idéia lamarckista da hereditariedade de caracteres adquiridos também exige uma distinção genótipo-fenótipo, para diferenciar a hereditariedade lamarckista da mera infecção ou contágio.

Por razões que ainda permanecem muito obscuras para mim (apesar de nossas longas conversas e extensa correspondência), em algum momento depois de 1999 Nelson começou a abandonar a distinção genótipo-fenótipo (e replicador-interator) em sua economia evolucionária. Acertadamente ele sublinha que os mecanismos da evolução biológica e socioeconômica são muito diferentes. Mas essa não é uma boa razão para abandonar os conceitos de replicador ou interator, que na literatura são definidos como termos muito genéricos. Eles não nos prendem a DNA ou a genes. Nelson sabia que os mecanismos da evolução biológica e socioeconômica são muito diferentes quando usou a metáfora de "rotinas como genes" em 1982. Suas razões para mudar de opinião são inadequadas e pouco claras.

Eu, pelo contrário, penso que a distinção replicador-interator é importante para entender o processo evolucionário em geral e o crescimento potencial da complexidade em particular. Sem a distinção replicador-interator não podemos ver a diferença entre contágio e difusão, por exemplo, e mecanismos mais sofisticados envolvendo armazenamento e replicação de informações com soluções para problemas de adaptação. Creio que esses mecanismos evolucionários mais sofisticados se encontram no mundo natural tanto quanto no mundo social. De que outra forma podemos explicar a rápida evolução de instituições humanas e tecnologias complexas nos poucos milênios mais recentes?

ESTUDOS AVANÇADOs - Como você resumiria sua controvérsia sobre instituições com Douglas North?

G. M. H. - Douglas North é um pensador extremamente importante e influente. Ele conseguiu realizar muitas coisas. Gosto especialmente do modo 
como ele agora está introduzindo idéias sobre cognição na explicação de mudanças econômicas e institucionais. Ele enfoca a maneira pela qual disposições ou preferências de agentes podem mudar por causa de fatores cognitivos. Isso admite a possibilidade de mudanças endógenas nas preferências e aproxima North do institucionalismo original de Veblen, Commons e outros. Vários estudiosos notaram essa convergência.

No início da década de 1960, deparei com muitas afirmações de que organizações não são instituições, que citavam North para reforçar a idéia. Reli as passagens relevantes na obra de North e notei que ele de fato não disse isso, embora algumas de suas afirmações sejam ambíguas e pouco claras. A idéia de que as organizações não são instituições é um tanto estranha, porque se as instituições constituem "as regras do jogo" (como muitas vezes diz North), então o mesmo vale para as organizações, especialmente do ponto de vista dos indivíduos que estão nelas. As organizações também são sistemas de regras.

No fim, entrei em contato com North sobre o caso e trocamos uma breve correspondência. Ele deixou claro que não estava primeiramente interessado na análise da dinâmica interna de uma organização, e tratava as organizações como atores singulares em sua obra. Mas aceitou que as organizações eram sistemas de regras, e também instituições. Publiquei trechos dessa correspondência na edição de março de 2006 da revista Journal of Economic Issues.

Outra questão que levantei com North foi sua terminologia obscura de "regras formais" e "constrangimentos informais". Muitos outros autores escrevem sobre "instituições formais e informais" sem se preocupar em explicar o que querem dizer com esses termos.

De fato, eles podem significar coisas diferentes: "formal" pode significar legal, projetado, codificado ou codificável. Além disso, North parece sugerir que todas as regras são "formais". Isso implicaria que todas as instituições são "formais" também. Em meu artigo fiz um apelo por mais cuidado e clareza na utilização desses termos.

Estudos AvanÇADOs - Qualé a sua avaliação das contribuições de Nicholas Georgescu-Roegen?

G. M. H. - Georgescu-Roegen foi um dos mais interessantes e criativos economistas do século XX. Um de seus numerosos feitos foi enfatizar a importância de questões ambientais e ecológicas para os economistas. Hoje, essas questões tornam-se cada vez mais urgentes e importantes.

A utilização que ele faz de idéias da termodinâmica é muito interessante, mas ainda não estou convencido de seu valor definitivo. É interessante notar que ele ignorou avanços recentes na termodinâmica envolvendo sistemas-fora-doequilíbrio. Outro problema é que o arcabouço termodinâmico não nos fornece um arcabouço adequado para fazer avaliações do bem-estar social.

Georgescu-Roegen é, contudo, um pensador extremamente importante e suas contribuições merecem mais atenção do que recebem. 


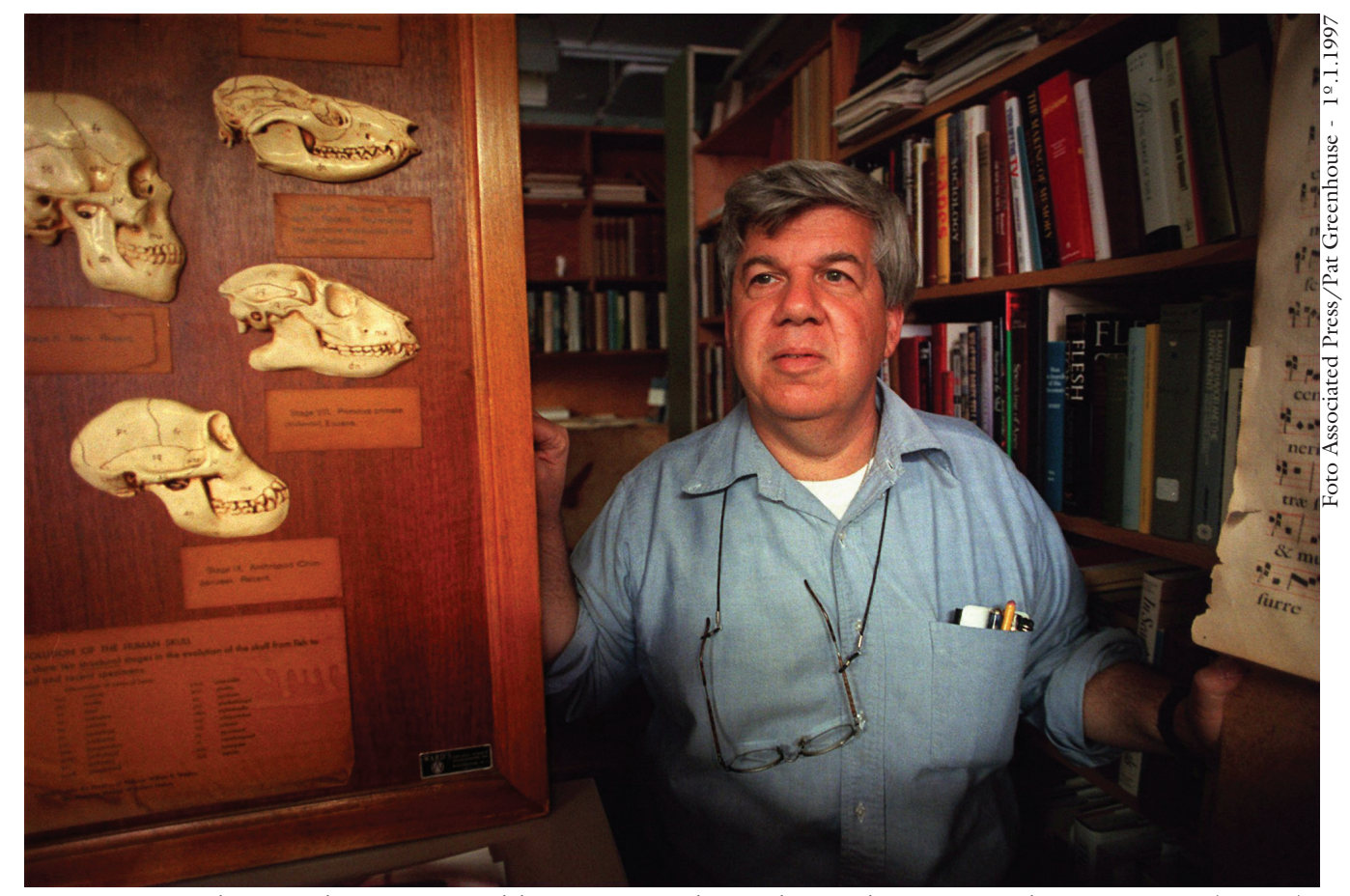

O pesquisador Stephen Jay Gould no Museu de Zoologia da Harvard University (EUA).

ESTUDOS AVANÇADOS - Quais são as questões mais importantes para a pesquisa em economia evolucionária?

G. M. H. - A economia evolucionária é atualmente uma vasta corrente de opiniões, contendo muitas visões diversas e um número grande e crescente de participantes. Áreas de pesquisa bem-sucedidas incluem os temas de economia industrial, rotinas organizacionais, comportamento do consumidor, tecnologia, política da ciência, ecologia, sistemas complexos e muitos outros. Os modos de pesquisa variam do empírico e aplicado, por meio de modelos formais, a questões filosóficas atinentes à ontologia. Em conseqüência disso, minha tentativa de enumerar "as questões mais importantes" é fatalmente limitada e parcial.

Pessoalmente, estou muito satisfeito com o fato de haver agora mais discussão dos fundamentos filosóficos da economia evolucionária. Isso nos ajuda a entender os arcabouços conceituais compartilhados por economistas evolucionários, bem como as diferenças de abordagens teóricas. Um esforço paralelo, com o qual também me envolvi, é o de mostrar como os princípios abstratos essenciais do darwinismo também se aplicam a entidades socioeconômicas em evolução tais como empresas. Já discuti algumas dessas questões envolvidas nessa pesquisa em resposta a perguntas anteriores.

Os economistas evolucionários têm-se mostrado mais inclinados do que seus colegas tradicionais a tomar emprestadas idéias de outras disciplinas, tais como psicologia, sociologia, antropologia e biologia. Mas deveríamos discutir mais indagando se há uma boa razão para manter esses limites disciplinares. Isso é particularmente importante para a geração mais jovem de economistas evo- 
lucionários que tem de estabelecer seu nicho profissional em alguma disciplina. O objetivo final deveria favorecer uma ciência social unificada. Pelo menos essa questão deveria estar na pauta.

Outra prioridade importante é desenvolver as implicações políticas das abordagens evolucionárias e um arcabouço evolucionário para a geração e avaliação de políticas. Alguns economistas evolucionários deram passos importantes nessa direção, mas ainda nos resta um longo caminho.

Não quero, porém, elaborar um grande plano para os economistas evolucionários. Confio na capacidade crítica de outros para desenvolver trabalhos em áreas aparentemente promissoras. Devemos celebrar a diversidade e o pluralismo. Desde a década de 1980, os economistas evolucionários estabeleceram prósperas redes nacionais e internacionais em que novas idéias e resultados podem ser discutidos e avaliados. Vamos construir sobre os bons êxitos do passado, e permanecer críticos, mas de mente aberta em nossa recepção do que é novo.

Nota

I Entrevista realizada por José Eli da Veiga, que registra seus agradecimentos pelas excelentes sugestões dos professores Eleutério Prado (FEA-USP), Arilson Favareto (UFABC) e dos pós-graduandos Andrei Cechin (Procam-USP) e Thiago M. R. Silva (IPEUSP).

Tradução de Lenita Maria Rimoli Esteves e Almiro Pisetta. O original em inglês - Darwinismo and social sciences: a possible dialogue - encontra-se à disposição do leitor no IEA-USP para eventual consulta. 